\title{
EQUIPE DE ENFERMAGEM E COMPLEXIDADES DO CUIDADO NO PROCESSO DE MORTE-MORRER
}

\author{
NURSING TEAM AND THE COMPLEXITIES OF CARE IN \\ IN THE DEATH/DYING PROCESS
}

\begin{abstract}
Tania Cristina Schäfer Vasques ${ }^{1}$ (iD) (0000-0002-6314-9887), Valéria Lerch Lunardi ${ }^{1}$ (DD (0000-0002-0380-1829), Priscila Arruda da Silva ${ }^{1}$ (iD)(0000-0002-5359-8646), Liziani Iturriet Avila ${ }^{1}$ (iD) (0000-0002-0093-1863), Rosemary Silva

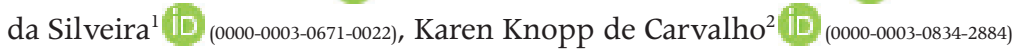

${ }^{1}$ Universidade Federal do Rio Grande, Rio Grande, Rio Grande do Sul, Brasil.

$<$ patitaarruda@yahoo.com.br>

${ }^{2}$ Universidade Federal de Pelotas, Pelotas, Rio Grande do Sul, Brasil.

Resumo Compreender como os trabalhadores da equipe de enfermagem se percebem na inter-relação complexa no cuidado ao indivíduo enfermo e seu familiar cuidador no processo de morte e morrer. Pesquisa qualitativa, desenvolvida em Hospital Universitário no período de março a junho de 2016, inspirada na metodologia de Leininger. Participaram 24 familiares cuidadores e 47 trabalhadores da equipe de enfermagem como informantes gerais, dos quais 18 como informantes-chave. A coleta de dados foi realizada por meio de entrevistas semiestruturadas, cujo enfoque foi a autopercepção da equipe no referido processo, contemplando os obstáculos e a complexidade nessas inter-relações no ambiente hospitalar. Mediante análise, com base no referencial teórico da complexidade de Edgar Morin, destacam-se como principais obstáculos: a sobrecarga de trabalho, o despreparo do profissional e a falta de apoio institucional. Quanto à complexidade das relações, destacam-se questões relacionadas: à competência profissional do cuidado, às necessidades das famílias, à valorização dos trabalhadores e sua repercussão para a inter-relação com o indivíduo enfermo e familiar cuidador. Acredita-se que tal estudo poderá levar os profissionais de enfermagem a uma reflexão e avaliação do seu fazer diário em relação aos cuidados com os indivíduos em seu processo de morte e morrer e seu familiar cuidador. Palavras-chave morte; doente terminal; enfermagem; inter-relação; família.
Abstract To understand how the nursing team workers perceive themselves in the complex interrelationship in the care provided to the ill individual and their family member who acts as carer in the death/dying process. This qualitative research was conducted in a university hospital between March and June 2016 and inspired by the Leininger methodology. A total of 24 family members who were carers and 47 nursing team workers as general informants, 18 of which were key informants. Data collection was performed through semistructured interviews, whose focus was the self-perception of the team regarding the aforementioned process, contemplating the obstacles and the complexity of these interrelationships in the hospital setting. Through an analysis based on Edgar Morin's theoretical framework of complexity, the work overload, the lack of competence on the part of the professional, and the lack of institutional support stand out as the main obstacles. Regarding the complexity of the relationships, questions related to the professional competence regarding the care, the needs of the family, the appreciation of the workers and its repercussion to the interrelationship with the ill individual and their relative that acts as carer stand out. We believe this study can cause the nursing professional to reflect upon and assess their daily practices in relation to the care provided to the individuals in their death/dying process and to their relatives that act as carers.

Keywords death; terminally-ill individuals; nursing; interrelationship; family. 


\section{Introdução}

Segundo a Organização Mundial de Saúde (OMS, 2015), nos últimos tempos, as doenças crônicas não transmissíveis, como o câncer e demência, dentre outras, têm aumentado significativamente, na medida em que a população envelhece. Seus respectivos tratamentos, comumente, exigem tolerância tanto dos indivíduos enfermos como das famílias que vivenciam esse processo, sendo este, muitas vezes, acompanhado de sofrimento e de sentença de morte. Ressalta-se que uma patologia incurável se torna causadora de um grande desgaste físico e mental para todos os envolvidos neste contexto, (indivíduo enfermo, família e equipe de saúde), dificultando a interação entre o familiar cuidador (FC) e profissionais de saúde (Santin e Klafke, 2011).

Quando os profissionais de saúde cuidam de enfermos no processo de morte e morrer, em ambiente hospitalar, as interações também podem se mostrar dificultosas e sofridas. Comumente, sentem-se responsáveis pela manutenção da vida desses indivíduos, enfrentando a morte como uma derrota profissional (Domingues et al., 2013). Assim, pode ocorrer a manifestação de sentimentos de angústia, frustração e impotência, tornando-se extremamente dolorosas as interações com os indivíduos e seus FCs (Domingues et al., 2013; Kovács, 2012). Salienta-se que, nesses ambientes, geralmente, prioriza-se a cura dos indivíduos enquanto o processo de morrer se torna desmotivador e sem sentido aos profissionais de saúde (Kovács, 2012).

Dentre os profissionais da equipe de saúde, no hospital, a equipe de enfermagem (EE) caracteriza-se por sua permanência e continuidade na prestação de cuidados ao indivíduo enfermo e suas famílias, vivenciando sua dor e sofrimento no processo de morte e morrer. De acordo com Medeiros e Lustosa (2011), a presença e o acompanhamento da EE no momento de finitude a torna um possível alvo de revolta e frustração dos indivíduos enfermos e seus FCs.

Os trabalhadores da EE, apesar de sua identidade com ações de cuidado, nem sempre estão preparados física e emocionalmente para lidar com os indivíduos que vivenciam esse processo e seus FCs. Dessa forma, os profissionais podem não saber o que falar ou fazer diante dessa fase da vida, retraindo-se ou gerando sofrimento em si mesmos. Priorizam, por fim, inter-relações com aqueles que têm possibilidade de cura, em uma tendência de fuga e negação, para se afastarem desse enfrentamento com o processo de morte e morrer; a equipe tende, portanto, a repudiar possíveis conexões que poderiam se formar nessa fase, possivelmente em decorrência da angústia gerada pela consciência de sua própria morte (Albertoni et al., 2013).

É possível identificar, nesse sentido, que a EE não está programada nem preparada para enfrentar o cuidar no processo de morte e morrer, uma vez que é um fenômeno que contribui para uma maior consciência de si mesmo e de sua própria finitude (Morin, 1997). De acordo com o referencial de 
Edgar Morin $(1997 ; 2013 ; 2014)$, o processo de morte e morrer é permeado pela incompletude, que requer interconexão entre os envolvidos no processo de cuidar. A compreensão do todo, do disjunto, do inseparável faz com que as inter-relações e os diálogos sejam importantes nessas dinâmicas no processo de finitude.

Esse estudo justifica-se pela compreensão de que as questões ligadas às inter-relações no processo de morte e morrer, entre a tríade EE, enfermo e FC, são assuntos considerados encobertos e ocultos, ficando no esquecimento do processo de cuidar. Entretanto, são questões que precisam ser discutidas, desde o momento da descoberta da doença incurável à elaboração do luto.

Nesse contexto, frente a possíveis dificuldades dos trabalhadores da EE em se inter-relacionar com o indivíduo enfermo e a FC no processo de morte e morrer no ambiente hospitalar, o presente estudo tem como objetivo: compreender como a EE se percebe na inter-relação complexa de cuidado ao indivíduo enfermo e seu FC no processo de morte e morrer em ambiente hospitalar.

\section{Método}

Trata-se de estudo com abordagem qualitativa, inspirado no caminho metodológico, proposto por Leininger (1985) ${ }^{1}$. Como referencial teórico, optou-se pelo pensamento complexo de Edgar Morin (2013) ${ }^{2}$. A pesquisa foi desenvolvida $^{3}$ em um Hospital Universitário do interior do Rio Grande do Sul, mais especificamente na Unidade de Clínica Médica (UCM).

O estudo teve, como informantes gerais, 24 FC de indivíduos em processo de morte e morrer e 47 trabalhadores da EE, que participaram da fase de observação. A opção pelos trabalhadores da EE como informantes decorreu do entendimento de que são os profissionais que melhor oportunizam a efetivação e continuidade do cuidado.

Os dados foram coletados de março a junho de 2016, totalizando $172 \mathrm{~h}$ de observação, realizadas por todos os informantes (familiares, pacientes e trabalhadores de enfermagem). Tais observações referiram-se às interrelações entre os trabalhadores da EE, FC e indivíduos em processo de morte e morrer, atentando aos diálogos construídos, à formação ou não de vínculos de afeto e confiança, às ações e condutas de cuidado da EE e dos FC, dentre outros.

Dentre os trabalhadores da EE, 18 foram selecionados como informanteschave, ou seja, aqueles com maior potencial para revelar informações consistentes, mediante entrevistas semiestruturadas, com duração de 40-75 minutos. É importante pontuar que, durante as entrevistas, foram trazidos alguns elementos da observação, o que possibilitou a reflexão do trabalhador da EE, bem como a validação dos dados. A escolha desses informantes-chave ocorreu com base em alguns critérios de inclusão durante a observação dos informan- 
tes gerais: manifestação de sensibilidade ou sua ausência, para tornar menos sofrido o processo de morte e morrer. Foram selecionados, no mínimo, dois profissionais da EE de cada categoria de todos os turnos de trabalho. O total de participantes foi determinado pela saturação dos dados(Leininger, 1985).

Assim, realizaram-se quatro fases de observação (não participante; menos participação e mais observação; mais participação e menos observação; e observação reflexiva). Além dessas, houve uma fase de entrevista para aprofundar aspectos observados quanto à inter-relação de cuidado do trabalhador da EE com o indivíduo enfermo e seu FC no processo de morte e morrer em ambiente hospitalar e, por fim, quatro fases de análise simultânea.

A primeira etapa ocorreu após a primeira e segunda fases da observação, na qual foram analisados os informantes gerais, com base em suas inter-relações com o FC, o indivíduo em processo de morte e morrer e os diários de campo, já sinalizando os possíveis informantes-chave.

A segunda etapa de análise ocorreu depois da terceira observação, na qual, por meio do critério de inclusão supracitado, os informantes-chave foram escolhidos para serem entrevistados.

A terceira ocorreu após a entrevista que buscou identificar comportamentos e ações, além da análise contextual. A quarta fase referiu-se à síntese dos dados, à abstração das categorias e às formulações teóricas referentes ao tema (Leininger, 1985).

Assim, o processo de análise incluiu o que foi observado pela pesquisadora e o que foi expresso pelos informantes nas entrevistas, bem como a compreensão obtida pela pesquisadora (Silveira et al., 2012).

O processo de coleta dos dados iniciou-se após a aprovação do Comitê de Ética e Pesquisa na Área da Saúde (CEPAS), mediante o parecer 16/2016, CAAE: 52938816.7.0000.5324. Respeitaram-se as recomendações da Resolução $\mathrm{n}^{\circ} 466 / 2012$ do Conselho Nacional de Saúde.

\section{Resultados e discussão}

Dos 18 informantes-chave da EE, cinco são enfermeiros, 11 técnicos de enfermagem e dois, auxiliares de enfermagem; suas idades variam entre 26 e 52 anos, com tempo de serviço na unidade entre seis meses e cinco anos; oito têm dupla jornada de trabalho ou frequentam curso universitário à noite.

O método utilizado possibilitou gerar constructos teóricos que conduziram à delimitação de duas categorias: 'Inter-relação conectada no cuidado no processo de morte e morrer: obstáculos da equipe de enfermagem' e 'Complexidade das relações no cuidado no processo de morte e morrer: conflitos dos trabalhadores da equipe de enfermagem'. 


\section{Inter-relação conectada no cuidado no processo de morte e morrer: obstáculos da equipe de enfermagem}

O ambiente hospitalar, por reunir um número significativo de indivíduos que necessitam de atenção e cuidado, precisa ser um local de acolhimento, de conexão entre os sujeitos, que proporciona o alívio de dores físicas e emocionais. Os indivíduos necessitam ser vistos na sua totalidade, no seu contexto de vida, conectados por trabalhadores que os assistem, sendo também amparados nesse processo.

A presente categoria aborda os obstáculos que o trabalhador da EE visualiza na inter-relação complexa com o indivíduo enfermo e seu FC. Alguns desses entraves são a sobrecarga de trabalho na unidade, bem como a falta de continuidade no cuidado prestado ao indivíduo enfermo, prejudicando as interações. Além disso, há certo despreparo para cuidar de indivíduos no processo de morte e morrer, e acarreta uma aparente dessensibilização no cuidado durante o processo de finitude de vida.

A maioria dos trabalhadores da EE demonstrou que sua sobrecarga de trabalho na unidade, tal como a constatação da falta de continuidade no cuidado prestado ao indivíduo enfermo, cuidado esse de responsabilidade da enfermagem, parece dificultar a dinâmica de funcionamento da unidade, prejudicando suas interações na equipe e com os indivíduos enfermos e seus FCs:

Quando tem muitos pacientes acamados que necessitam de mim e que eu não consigo vencer, porque é um técnico para quatro, cinco, seis acamados, isso me deixa doente! Porque eu vou pra casa com sensação de que meu dever não foi cumprido, que eu vim só mecanicamente e trabalhei (EE18).

Enquanto nós tivermos essa realidade em que tem um enfermeiro para 45-47 pacientes e tem que dar conta de múltiplas demandas, difícil formar vínculos e dar atenção, porque o tempo é curto, corrido e com muitas responsabilidades (EE12).

Tu chega para teu plantão e, às vezes, tem um acesso perdido porque não cuidaram; o soro está com data de mais de $24 \mathrm{~h}$ e não passou nem $100 \mathrm{ml}$, sem acesso e daí tu vê que aquilo ali é falta de cuidado, tu não vê uma continuidade do que tu fez ontem (EE13).

Já aconteceu de saberes que vai pegar a enfermaria do fulano, do turno anterior, e tu dizer: 'estou ralada hoje', porque ficas com as tuas responsabilidades do turno e mais o que o outro deixou, é esse tipo de comentário (EE15). 
Tendo em vista uma aparente desordem organizacional observada, a sobrecarga de trabalho da EE parece desencadear entraves e contradições que podem afetar o cuidado global dos indivíduos internados, bem como suas inter-relações, principalmente no processo de morte e morrer. Assim, as relações entre os indivíduos em ambiente hospitalar sofrem constantes interferências, comprometendo o atendimento de qualidade e a interconexão das relações, o qual tem ocasionado sobrecarga de trabalho, repercutindo na saúde física e mental do trabalhador (Santos et al., 2013).

De acordo com Rezende e Neto (2013), a sobrecarga de trabalho contribui para desconstruir relações que deveriam ser interligadas, tornando a criação de elos de confiança e relacionais difícil. O estabelecimento de tais laços contribui para a prestação de uma assistência digna nesse processo de morte e morrer. Nesse contexto, constata-se que as instituições hospitalares, por sua configuração complexa, envolvem aspectos sistêmicos e intraorganizacionais, escolha de metas, recursos disponíveis, formas de contratação de pessoal e remuneração. Tais instituições, bem como os atendimentos a que os trabalhadores estão expostos no cotidiano, devem ser analisados de modo global e integrado, a fim de abarcar o bem-estar de todos os envolvidos nesse ambiente de cuidado (Novaretti et al., 2014).

Além disso, diante da sobrecarga de trabalho, trabalhadores alegam a falta de continuidade do cuidado ao indivíduo enfermo, uma vez que, em alguns turnos, o cuidado não é realizado a contento, contribuindo para que determinados profissionais se reconheçam como mais responsáveis e mais sobrecarregados do que outros de turnos diferentes. Tais insatisfações e caos existentes no ambiente de trabalho podem ocasionar nos trabalhadores desânimo e falta de vontade na realização das atribuições do dia a dia laboral, acarretando e intensificando rupturas nas inter-relações no ambiente hospitalar.

Frente a tais descontinuidades e rupturas nas ações de cuidado, o indivíduo enfermo e seu FC podem ficar desassistidos física e emocionalmente, principalmente quando vivenciam o processo da finitude. Portanto, é imprescindível um olhar sistêmico, em que o todo precisa ser visualizado, sem que, contudo, as particularidades desse quadro sejam perdidas. É preciso, por fim, que essa complexa junção se torne complementar, agregando ao invés de dispersar. Segundo Morin (2014), o todo institucional necessita olhar as partes constituídas pelos indivíduos que fazem parte da instituição. A rotatividade e a falta de entrosamento de toda a equipe e entre os turnos de trabalho afastam os trabalhadores da formação dos vínculos, fragilizando, então, as relações de confiança no ambiente hospitalar, o que possibilita levá-los a um maior desgaste físico e emocional (Garcia et al., 2012).

Os trabalhadores da EE reconhecem, também, seu despreparo para cuidar de indivíduos no processo de morte e morrer, o que pode contribuir para sua aparente dessensibilização: 
O sofrimento (causado pela morte do paciente) é mais relacionado a nossa incapacidade de cuidar do que o fato da pessoa estar morrendo [...] a gente não sabe como adentrar nesses momentos [...] para nós, acaba sendo mais uma demanda (EE12).

Alguma coisa era importante vir de fora assim, um suporte ou mesmo uma capacitação, uma coisa até para a gente lidar melhor com isso (EE15).

Quando eu comecei a atuar, fiquei um pouco chocada ao cuidar desses pacientes, mas, depois, com o convívio do dia a dia, tu acabas te acostumando (EE8).

O preparo do trabalhador para interagir e cuidar do indivíduo no seu processo de finitude e de seu FC tem sido praticamente negligenciado desde a sua formação, levando-o a fazer essa aprendizagem no seu dia a dia; como nesta pesquisa, muitos parecem se dessensibilizar frente à necessidade de cuidado do indivíduo na finitude (Rosa e Couto, 2015). Enfatiza-se a busca pelo tratamento em prol da cura, não preparando esses trabalhadores para cuidar na finitude, o que pode favorecer o afastamento do trabalhador, percebido, frequentemente, como manifestação de negligência na assistência.

Reitera-se que a morte ainda é comumente negada na sociedade atual. Mesmo estando constantemente presente no ambiente hospitalar, a tendência é que os profissionais da saúde tentem negá-la, sem enfrentá-la realmente. Assim, lidar com a proximidade da morte sem o devido preparo pode levar, gradativamente, o trabalhador a uma postura de dessensibilização. Esta favorece atitudes mecanizadas na interação com indivíduos em seu processo de morte e morrer, bem como seu FC, que comumente sofre junto(Duarte, Almeida e Popim, 2015).

O indivíduo, no entanto, precisa ser visto em sua totalidade, em seu contexto de vida e de morte, pois o processo de morte e morrer também é parte integrante da existência. De maneira geral, as grades curriculares contemplam questões relacionadas à vida, à cura e ao tratamento, sem que exista uma reflexão mais voltada para a finitude da vida e seu inter-relacionamento nas situações de sofrimento (Alves e Cogo, 2014). Nesse sentido, o preparo e a reflexão dos trabalhadores da EE, acerca do processo de morte e morrer, precisam ser discutidos com base em referenciais capazes de ampliar o pensamento, tornando-o complexo, multidimensional, e disposto a considerar as influências internas e externas do indivíduo, em oposição a uma concepção linear e fragmentada (Morin, 2014).

De acordo com Duarte, Almeida e Popim (2015), a percepção de incapacidade ao interagir nessas situações de sofrimento, ou a noção de que não é possível lidar com a carga de trabalho imposta, pode gerar depressões, desmotivações e sentimentos de desistência da profissão. Percebeu-se, no estudo em questão, que o trabalhador da EE se sente cuidando de todos e que, apesar 
de fragilizado, precisa continuar trabalhando, mesmo que automaticamente. Assim, a falta de apoio institucional deve ser compreendida como uma dificuldade para efetivar as inter-relações no ambiente hospitalar:

O funcionário tem que ter um psicólogo, o funcionário tem que ter um acompanhamento, para nós sabermos lidar com certas circunstâncias como a morte, que é tão difícil (EE5).

Não tens aquele tempo de sentar e conversar, nem psicologicamente tu estás preparado para essas discussões de morte e morrer (EE1).

O apoio psicológico aos trabalhadores poderia favorecer o enfrentamento das situações estressantes e adversas que surgem no cotidiano das interrelações, contribuindo na elaboração do sofrimento em situações difíceis, como a assistência no processo de morte e morrer (Hohendorff e Melo, 2009).

No ambiente hospitalar, os psicólogos podem atuar tanto no contexto familiar, quanto junto aos trabalhadores da EE, contribuindo para minimizar e ressignificar o processo de sofrimento diante do cuidar de indivíduos na finitude. Mediante o uso de técnicas, são capazes de proporcionar a aproximação e religação no convívio e cuidado a esses indivíduos e seus FCs, de modo a promover um ambiente adequado de escuta e diálogo. Desse modo, os psicólogos podem facilitar o desenvolvimento da autonomia organizacional do indivíduo enfermo e seu FC e contribuir com os trabalhadores para um melhor enfrentamento nas inter-relações com os envolvidos nesse ambiente, preservando sua saúde mental e emocional (Carvalho e Martins, 2015).

\section{Complexidade das relações no cuidado no processo de morte e morrer: confli- tos dos trabalhadores da equipe de enfermagem}

Essa categoria aborda a complexidade das relações no cuidado no processo de morte e morrer, envolvendo conflitos dos trabalhadores da EE. Esses conflitos fragilizam as inter-relações no processo de morte e morrer de diversos modos. Algumas formas de tensões são expressas pelos questionamentos dos FCs acerca da competência na realização dos cuidados no indivíduo enfermo; dúvidas quanto ao cumprimento das atribuições; conflitos com a equipe médica quanto à valorização e ao reconhecimento do trabalhador da EE.

Dessa forma, verifica-se que alguns trabalhadores da EE consideram que os FCs poderiam ser mais participativos e atuantes nos cuidados aos seus indivíduos enfermos no ambiente hospitalar. Contraditoriamente, reconhecem que esses FCs precisariam ter maior respeito e atenção às suas solicitações por parte da própria EE: 
Para mim, cuidador dentro do hospital deveria prestar todo o cuidado a partir da higiene desse paciente, até de mudança de decúbito. Se não consegue virar direito, chama a gente para ajudar, mas a maioria deles não faz isso, muitos ficam ali, só sentados [...] ou tem três pessoas junto da paciente e ficam pedindo para ti trocar a fralda, poxa! É a tua mãe que tá ali [...] isso incomoda (EE4).

O familiar também, às vezes, fica no hospital, querendo que a gente faça as coisas para o paciente, que eles poderiam fazer (EE16).

A atenção tem que existir porque é isso que eles esperam da gente, eles comentam 'fulano, tu fala e não tá nem aí, não é o pai dele, não um familiar dele precisando...'; eles se queixam bastante. Às vezes, é só uma fralda que tu tem que trocar (EE15).

Às vezes, eles chegam correndo pedindo para irem lá no paciente e o colega não vai, isso me angustia, me dá vontade de ir, só que muitas vezes se tu vai, tu vai arrumar mais uma indisposição com o teu colega ou o teu colega vai fazer de conta que não vai ouvir as outras vezes que o familiar vai chamar e tu vai sempre... aí tu atende todos os teus e mais os do colega (EE7).

A hospitalização de um ente querido, geralmente, ocasiona mudanças no cotidiano da família, produz sentimentos de angústia e ansiedade diante de uma doença incurável, aliados à insegurança frente à internação(Freitas, Mussi e Meneses, 2012). Assim, discute-se a complexidade do cuidar em um ambiente contraditório, o hospital, no qual os indivíduos o compreendem como a aproximação do evento da morte e, simultaneamente, fomentam a esperança da cura, por meio de tecnologias.

De acordo com as observações realizadas no presente trabalho, foi possível verificar que os FCs, quando interagem com o indivíduo enfermo no ambiente hospitalar, receiam tocar no indivíduo, pois temem feri-lo, contagiar-se com sua doença, por não lhe ser íntimo, ou, ainda, por considerarem que a prestação de cuidado no hospital compete aos trabalhadores da EE.

Estar em ambiente hospitalar, apesar de cansativo, comumente parece trazer maior segurança e conforto ao FC, pois, desse modo, ele não será cuidador sozinho, com todas as responsabilidades decorrentes, fato ratificado nas observações do presente estudo. Os trabalhadores da EE discutiram também a questão do respeito e atenção a esses FCs que, muitas vezes, podem se sentir deslocados em um meio hospitalar estranho e sofrido. Portanto, alguns participantes do estudo manifestaram a importância em atender aos FCs, quando solicitados, visualizando esse indivíduo integrado, interconectado e ligado a esse meio estressante e hostil. 
O cuidar nesse ambiente complexo implica estabelecer relações entre os indivíduos envolvidos, em que os trabalhadores da EE precisam analisar como vem sendo feito o cuidado e o ser que o recebe. Cada indivíduo é único, com suas fragilidades e potencialidades a serem consideradas nesse contexto de cuidado. As inter-relações tornam-se ainda mais complexas nesse ambiente diverso e multifacetado do hospital, quando os trabalhadores da EE não conseguem visualizar a necessidade do outro, negligenciando, por vezes, as queixas e solicitações dos FCs (Dias et al., 2014), o que foi referido pelos próprios trabalhadores entrevistados.

A presença física e a atuação desses trabalhadores junto aos indivíduos sofridos podem fortalecer e ressignificar essa fase da vida, proporcionando-lhes segurança e conforto. Dar atenção e se fazer presente nesse cuidado humano torna-se fundamental e imprescindível para a valorização do que o indivíduo enfermo e seu FC desejam ou têm interesse nesse momento de finitude (Lima e Oliveira, 2015).

Trabalhadores manifestaram indignação pelo fato de alguns colegas, por vezes, não valorizarem as solicitações dos indivíduos enfermos e seus FCs, desconsiderando suas necessidades de atenção e presença, importantes na finitude e na reorganização de todo esse processo. O fazer técnico precisa convergir nas ações de cuidado e na forma como ele ocorrerá; assim, esse processo precisa ser compreendido como integral e baseado na relação com o outro, sendo esta, muitas vezes, antagônica e complementar (Lima e Oliveira, 2015).

Trabalhadores da EE manifestaram vivenciar conflitos decorrentes da aparente falta de reconhecimento e valorização por parte da equipe médica, com repercussões na inter-relação complexa no cuidado ao indivíduo enfermo e seu FC:

A enfermagem, perante a medicina [...], o que a gente fala, eles não absorvem sabe?! Não dão atenção, se está prescrito um laxativo, faz! Pô, estou falando que o paciente já evacuou [...] o médico não tem confiança na enfermagem! Eu ou o enfermeiro falar, é indiferente para eles, e dependendo do enfermeiro do setor também não temos respaldo, nem mesmo da nossa chefia imediata [...] tenho muitos planos de abandonar a área da saúde e esse é um dos grandes motivos (EE5).

Aconteceu de eu estar na enfermaria e o residente estar e eu passar para ele: 'olha, o paciente tá hiperglicêmico, tá tanto o que eu faço?' E a pessoa não me responder [...]; ele me ignorou e foi lá conversar com a enfermeira (EE15).

Atitudes e ações reducionistas e lineares, na própria equipe e por parte da equipe médica, foram evidenciadas pelos trabalhadores da EE, com aparentes falhas e rupturas nos diálogos, desconexão e desvalorização. Esse quadro 
parece contribuir para sua desmotivação e afastamento do cuidado direto ao indivíduo enfermo e ao FC no processo de morte e morrer no hospital.

Considera-se que é preciso valorizar e cultivar a habilidade da comunicação perante um trabalho multiprofissional, a fim de transpor dificuldades e limitações encontradas no trabalho em equipe no ambiente hospitalar. Uma comunicação efetiva e com respeito entre os indivíduos que lidam com o sofrimento do outro pode contribuir para a qualidade do cuidado prestado, bem como para o fortalecimento pessoal do trabalhador inserido nesse meio, o qual se sente como parte de todo o processo de assistir (Cardoso et al., 2013).

Em um comportamento social, a interação entre os indivíduos e o ambiente dependerá das retroalimentações do próprio convívio e diálogo estabelecidos nesse contexto. Para Morin (2014), é possível afirmar que o trabalhador da EE precisa agir como um protagonista nessas interações, contribuindo para o processo de autorregulação no ambiente de cuidado.

Percebe-se que a relação entre os trabalhadores da EE e da equipe médica é, por vezes, desconectada, na medida em que o saber médico se sobrepõe ao saber dos trabalhadores da EE. Nesse sentido, os trabalhadores podem se sentir desmotivados, haja vista não serem suficientemente considerados como parte da equipe hospitalar. Assim, sua visibilidade e reconhecimento mostram-se fragilizados, o que afeta, também, a confiança do indivíduo enfermo e seu FC em relação ao trabalhador da EE.

Tendo em vista a complexidade da dinâmica, abre-se uma lacuna entre o trabalhador da EE e o indivíduo enfermo e seu FC, o que compromete a criação de vínculos para o desenvolvimento de uma assistência adequada no fim da vida. Ressalta-se que a comunicação entre os trabalhadores é de extrema importância para que as inter-relações possam se formar no ambiente hospitalar (Avila et al., 2013).

Por outro lado, quando o trabalhador da EE se sente reconhecido e parte importante na equipe de cuidado, desenvolve o seu fazer com maior comprometimento e satisfação, pois o local de trabalho passa a ser identificado como um ambiente em que goza de reconhecimento e valorização. Considera-se que, com essa satisfação, os trabalhadores poderão estar motivados a desenvolver um cuidado relacional com o indivíduo enfermo e seu FC, com maior qualidade (Silveira et al., 2012).

\section{Conclusão}

A complexidade envolvida nas inter-relações dos FCs com a EE e o indivíduo enfermo no seu processo de morte e morrer apontam para a necessidade do diálogo, da formação de vínculos e de confiança, os quais poderão contribuir para reduzir o distanciamento, a ruptura e o sofrimento de quem vivencia 
o processo de finitude, com a possibilidade de ressignificação do valor e o sentido do cuidado nessa fase do ciclo vital.

Ao analisar como os trabalhadores da EE se percebem na inter-relação complexa no cuidado ao indivíduo enfermo e seu FC no processo de morte e morrer, evidenciaram-se obstáculos, reforçando o quão complexas são as relações nesse processo.

Os obstáculos para a efetivação de inter-relações conectadas estão articulados, primordialmente, à sobrecarga de trabalho, despreparo dos profissionais de saúde para o cuidado nesse processo, dessensibilização e falta de apoio institucional.

A complexidade das relações no processo de morte e morrer em ambiente hospitalar relaciona-se: a conflitos com os FCs, quanto à competência na realização de cuidados ao indivíduo enfermo, assim como quanto à maior atenção às necessidades desses FCs; com a equipe médica, no que se refere ao reconhecimento e valorização dos trabalhadores da EE, dentre outras, com implicações nas inter-relações no cuidado ao indivíduo enfermo e seu FC.

Destaca-se, como principal lacuna neste estudo, a necessidade de compreender como esses indivíduos vivenciam a sua inter-relação com os trabalhadores da EE e o seu FC no ambiente hospitalar, a fim de complementar a investigação sobre o tema. Acredita-se que tal estudo poderá levar os trabalhadores da EE a uma reflexão e avaliação do seu fazer diário em relação aos cuidados com os indivíduos em seu processo de morte e morrer e seu FC.

\section{Colaboradores}

Tânia Cristina Schäfer Vasques foi responsável pela concepção, delineamento, execução da pesquisa, análise e interpretação dos dados e revisão crítica do artigo. Valéria Lerch Lunardi orientou a pesquisa e participou das etapas de delineamento, análise e interpretação dos dados e revisão crítica do artigo. Liziani Iturriet Avila e Rosemary Silva da Silveira trabalharam na redação e revisão crítica do manuscrito. Priscila Arruda da Silva e Karen Knopp de Carvalho trabalharam na revisão crítica do conteúdo e versão final do artigo. Os autores declaram não haver conflitos de interesse. 


\section{Financiamento}

O presente trabalho foi realizado com apoio da Coordenação de Aperfeiçoamento de Pessoal de Nível Superior (CAPES) com concessão de Bolsa de Doutorado.

\section{EQUIPO DE ENFERMERÍA Y COMPLEJIDADES DEL CUIDADO EN EL PROCESO DE MUERTE-MORIR}

Resumen Comprender como los trabajadores del equipo de enfermería se perciben en la interrelación compleja en el cuidado al individuo enfermo y su familiar cuidador en el proceso de muerte y morir. Estudio cualitativo, desarrollado en Hospital Universitario en el período de marzo a junio de 2016, inspirado en la metodología de Leininger. Participaron 24 familiares cuidadores y 47 trabajadores del equipo de enfermería como informantes generales, de los cuales 18 como informantes-clave. La obtención de datos fue realizada por medio de entrevistas semiestructuradas, cuyo enfoque fue la autopercepción del equipo en el referido proceso, contemplando los obstáculos y la complejidad en esas interrelaciones en el ambiente hospitalario. Mediante análisis, con base en el referencial teórico de la complejidad de Edgar Morin, se destacan como principales obstáculos: la sobrecarga de trabajo, la falta de preparación del profesional y la falta de apoyo institucional. En cuanto a la complejidad de las relaciones, se destacan cuestiones relacionadas: a la competencia profesional del cuidado, a las necesidades de las familias, a la valorización de los trabajadores y su repercusión para la interrelación con el individuo enfermo y familiar cuidador. Se cree que tal estudio podrá llevar a los profesionales de enfermería a una reflexión y evaluación de su rutina diaria en relación a los cuidados con los individuos en su proceso de muerte y morir y su familiar cuidador.

Palabras clave muerte; enfermo terminal; enfermería; interrelación; familia.

\section{Notas}

${ }^{1}$ Leininger reconhece na etnoenfermagem um método importante para a obtenção de fatos, sentimentos, percepção de mundo sobre determinada vivência, bem como outros dados que permitam a compreensão de situações e sentimentos reais, verdadeiros e modos de vida no seu cotidiano.

${ }^{2}$ De acordo com a teoria de Edgar Morin, a complexidade é compreendida como um tipo de pensamento que não separa, mas une e busca relações necessárias e interdependentes de todos os aspectos da vida humana. Morin compreende os conceitos sem considerálos concluídos, valorizando a circularidade da ordem e da desordem das inter-relações entre os indivíduos, bem como o processo dialógico do uno e do diverso ou do estável e da mudança, visualizando, com base na singularidade de cada um, possíveis interações, relações, interligações entre as partes envolvidas.

${ }^{3}$ Artigo extraído da tese de doutorado de Tânia Cristina Schäfer Vasques, intitulada: "Inter-relações no processo de morte e morrer em ambiente hospitalar", defendida no Programa de Pós-Graduação em Enfermagem, Universidade do Rio Grande, em 2016. Não há conflitos de interesse. 


\section{Referências}

ALBERTONI, Lucas I. et al. Análise qualitativa do impacto da morte sobre os estudantes de medicina da faculdade de medicina de São José do Rio Preto. Arquivos de Ciências da Saúde, São José do Rio Preto, v. 20, n. 2, p. 49-52, 2013. Disponível em: <http://repositorio-racs. famerp.br/racs_ol/vol-20-2/ID_529_abr-jun_2013. pdf >. Acesso em: 15 fev. 2019.

ALVES, Elcilene A. T. D.; COGO, Ana L. P. Percepção de estudantes de enfermagem sobre o processo de aprendizagem em ambiente hospitalar. Revista Gaúcha de Enfermagem, Porto Alegre, v. 35, n. 1, p.102-109, 2014. Disponível em: <http://www.scielo.br/pdf/rgenf/v35nl/ pt_1983-1447-rgenf-35-01-00102.pdf > . Acesso em: 15 fev. 2019

AVILA, Liziani I. et al. Implicações da visibilidade da enfermagem no exercício profissional. Revista Gaúcha de Enfermagem, Porto Alegre, v. 34, n. 3, p. 102-109, 2013. Disponível em: $<$ https://seer.ufrgs.br/RevistaGauchadeEnfermagem/article/view/37874>. Acesso em: 15 fev. 2019

CARVALHO, Jeane S.; MARTINS, Alberto M. A morte no contexto hospitalar: revisão de literatura nacional sobre a atuação do Psicólogo. Revista da Sociedade Brasileira de Psicologia Hospitalar (SBPH), Belo Horizonte, v. 18, n. 2, p. 129-142, 2015. Disponível em: <http:// pepsic.bvsalud.org/pdf/rsbph/v18n2/v18n2a09. pdf >. Acesso em: 15 fev. 2019.

CARDOSO, Daniela H. et al. Cuidados paliativos na assistência hospitalar: a vivência de uma equipe multiprofissional. Texto \& Contexto Enfermagem, Florianópolis, v. 22, n. 4, p. 1.134-1.141, 2013. Disponível em: <http:// www.scielo.br/pdf/tce/v22n4/32.pdf > . Acesso em: 15 fev. 2019.

DIAS, Matheus V. et al. Formação do enfermeiro em relação ao processo de morte-morrer: percepções à luz do pensamento complexo. Revista Gaúcha de Enfermagem, Porto Alegre, v. 35, n. 4, p.79-85, 2014. Disponível em: <http:// www.scielo.br/pdf/rgenf/v35n4/1983-1447rgenf-35-04-00079.pdf>. Acesso em: 14 fev. 2019.
DOMINGUES, Glaucia R. et al. A atuação do psicólogo no tratamento de pacientes terminais e seus familiares. Psicologia Hospitalar, São Paulo, v. 11, n. 1, p. 2-24, 2013. Disponível em: <http://pepsic.bvsalud.org/pdf/ph/vllnl/ vllnla02.pdf>. Acesso em: 15 fev. 2019.

DUARTE, Anaísa V.; ALMEIDA, Débora V.; POPIM, Regina C. Death within the medical undergraduate routine: students' views. Interface: Comunicação, Saúde, Educação, Botucatu, v. 19, n. 55, p. 1.207-1.219, 2015. Disponível em: <http://www.scielo.br/pdf/icse/v19n55/ en_1807-5762-icse-1807-576220141093.pdf $>$. Acesso em: 15 fev. 2019.

FREITAS, Katia S.; MUSSI, Fernanda C.; MENEZES, Igor G. Desconfortos vividos no cotidiano de familiares de pessoas internadas na UTI. Escola Anna Nery Revista de Enfermagem, Rio de Janeiro, v. 16, n. 4, p. 704-711, 2012. Disponível em: <http://www.scielo.br/pdf/ ean/v16n4/09.pdf> . Acesso em: 15 fev. 2019.

GARCIA, Alessandra B. et al. Prazer no trabalho de técnicos de enfermagem do prontosocorro de um hospital universitário público. Revista Gaúcha de Enfermagem, Porto Alegre, v. 33, n. 2, p. 153-59, 2012. Disponível em: <http://www.scielo.br/pdf/rgenf/v33n2/22. pdf>. Acesso em: 15 fev. 2019.

HOHENDORFF, Jean V.; MELO, Wilson V. Compreensão da morte e desenvolvimento humano: contribuições à Psicologia Hospitalar. Estudo pesquisa e psicologia, Rio de Janeiro, v. 9, n. 2, p. 480-492, 2009. Disponível em: $<$ http://pepsic.bvsalud.org/pdf/epp/v9n2/ v9n2a14.pdf>. Acesso em: 14 fev. 2019.

KOVÁCS, Maria J. Educadores e a morte. Revista Semestral da Associação Brasileira de Psicologia Escolar e Educacional, São Paulo, v. 16, n. 1, p. 71-81, 2012. Disponível em: $<$ http://www.scielo.br/pdf/pee/v16nl/08. pdf $>$. Acesso em: 13 fev. 2019.

LEININGER, Madeleine. Etnography and ethnonursing: models and modes of qualitative data analysis. Orlando: Grune \& Stratton, 1985. 
LIMA, Marcos P. O.; OLIVEIRA, Mônica C. X. Significados do cuidado de enfermagem para familiares de pacientes em tratamento paliativo. Rev Rene, Fortaleza, v. 16, n. 4, p. 593-602, 2015. Disponível em: <http://periodicos.ufc. br/rene/article/view/2752/2135>. Acesso em: 15 fev. 2019.

MEDEIROS, Luciana A.; LUSTOSA, Maria A. A difícil tarefa de falar sobre morte no hospital. Revista $S B P H$, Rio de Janeiro, v. 14, n. 2, p. 203-227, 2011. Disponível em: $<$ http://pepsic.bvsalud.org/pdf/rsbph/v14n2/ v14n2al3.pdf>. Acesso em: 16 fev. 2019.

MORIN, Edgar. O homem e a morte. Rio de Janeiro: Imago, 1997.

MORIN, Edgar. Método 1: a natureza da natureza. 3. ed. Porto Alegre: Sulina, 2013.

MORIN, Edgar. A cabeça bem-feita: repensar a reforma, reformar o pensamento. 17. ed. Rio de Janeiro: Bertrand Brasil, 2014.

NOVARETTI, Márcia C. Z. et al. Sobrecarga de trabalho da Enfermagem e incidentes e eventos adversos em pacientes internados em UTI. Revista Brasileira de Enfermagem, Brasília, v. 67, n. 5, p. 692-699, 2015. Disponível em: <http://www.scielo.br/pdf/reben/ v67n5/0034-7167-reben-67-05-0692.pdf>. Acesso em: 14 fev. 2019.

ORGANIZAÇÃO MUNDIAL DA SAÚDE. Relatório Mundial sobre envelhecimento e saúde. 2015. Disponível em:<http://www.who.int/ ageing/publications/world-report-2015/en/>. Acesso em: 15 fev. 2019.
ROSA, Danielle S. S.; COUTO, Selma A. O enfrentamento emocional do profissional de enfermagem na assistência ao paciente no processo da terminalidade da vida. Revista Enfermagem Contemporânea, Salvador, v. 1, n. 4, p. 92-104, 2015. Disponível em: <https:// www5.bahiana.edu.br/index.php/enfermagem/article/view/467/438>..Acesso em: 16 fev. 2019.

REZENDE, Maria C. C.; NETO, João L. Processos de subjetivação na experiência de uma equipe de enfermagem em oncologia. Revista Psicologia e Saúde, Campo Grande, v. 5, n. 1, p. 40-48, 2013. Disponível em: <http://www.gpec.ucdb.br/pssa/index. $\mathrm{php} / \mathrm{pssa} / \operatorname{article} / \mathrm{view} / 215>$. Acesso em: 15 fev. 2019.

SANTIN, Gisele; KLAFKE, Teresinha E. A família e o cuidado em saúde mental. Barbaroi, Santa Cruz do Sul, v. 34, n. 1, p. 146-60, 2011. Disponível em: <https://online.unisc.br/seer/ index.php/barbaroi/article/view/1643/1567> Acesso em: 14 fev. 2019.

SANTOS, José L. et al. Prazer e sofrimento no exercício gerencial do enfermeiro no contexto hospitalar. Escola Anna Nery Revista de Enfermagem, Rio de Janeiro, v. 17, n. 1, p. 97-103, jan./mar. 2013. Disponível em: <http://www. scielo.br/pdf/ean/v17nl/14.pdf $>$. Acesso em: 15 fev. 2019.

SILVEIRA, Rosemary S. et al. Percepção dos trabalhadores de enfermagem acerca da satisfação no contexto do trabalho na UTI. Enfermagem em Foco, Salvador, v. 3, n. 2, p. 93-96, 2012. Disponível em: <http://revista. portalcofen.gov.br/index.php/enfermagem/article/view/262/150>. Acesso em: 15 fev. 2019. 